\title{
TINOSPORA CORDIFOLIA AQUEOUS EXTRACT AMELIORATES THE SYSTEMIC INFECTION OF ASPERGILLUS FUMIGATUS IN BALB/C MICE
}

\author{
MASOOD A KHAN* \\ Department of Basic Health Sciences, College of Applied Medical Sciences, Qassim University, Buraydah, KSA. Email: a_khan@qu.edu.sa
} Received: 27 October 2018, Revised and Accepted: 03 January 2019

\begin{abstract}
Objective: The present study was aimed to assess the antifungal activity of Tinospora cordifolia aqueous extract (TCAE) against Aspergillus fumigatus infection.

Methods: TCAE was tested for in vitro antifungal activity against the isolates of $A$. fumigatus, Aspergillus flavus, and Aspergillus niger. To evaluate in vivo activity, various doses $(10,25$, and $50 \mathrm{mg} / \mathrm{kg})$ of TCAE were orally administered in A. fumigatus-infected mice for 7 days. The combination of prophylactic and therapeutic effect of TCAE was assessed by pre-treating the mice with $10 \mathrm{mg} / \mathrm{kg}$ of TCAE for 3 consecutive days before exposing them to A. fumigatus. Mice were treated with 10,25 , and $50 \mathrm{mg} / \mathrm{kg}$ doses of TCAE for 7 consecutive days' post- $A$. fumigatus infection. The effectiveness of TCAE was evaluated by monitoring the survival rate and assessing the fungal burden in the kidney of the treated mice.
\end{abstract}

Results: A. fumigatus-infected mice treated with TCAE at the doses of 25 and $50 \mathrm{mg} / \mathrm{kg}$ exhibited $50 \%$ and $20 \%$ survival rate, respectively, observed on day 40 post-treatment. Like to the survival data, the fungal burden was also found to be the lowest in the kidney of mice treated with TCAE at a dose of $50 \mathrm{mg} / \mathrm{kg}$. The results showed that pre-treatment with TCAE $(10 \mathrm{mg} / \mathrm{kg})$ followed by post-infection treatment with 10,25 , and $50 \mathrm{mg} / \mathrm{kg}$ of TCAE for 7 days resulted in $40 \%, 50 \%$, and $70 \%$ survival rate, respectively.

Conclusions: These results suggest that TCAE may potentially be considered for its possible use in the treatment of the systemic infection of A. fumigatus.

Keywords: Alternative medicines, Aspergillus fumigatus, Tinospora cordifolia, Fungal infections.

(C) 2019 The Authors. Published by Innovare Academic Sciences Pvt Ltd. This is an open access article under the CC BY license (http://creativecommons. org/licenses/by/4. 0/) DOI: http://dx.doi.org/10.22159/ajpcr.2019.v12i3.30984

\section{INTRODUCTION}

The therapeutic use of antibiotics has played a tremendous role in combating various infectious diseases [1]. Although the indiscriminate and extensive use of antifungals has resulted in the emergence of multidrug-resistant isolates of fungal pathogens, which are posing serious challenges to the clinicians [2]. Moreover, some antifungal agents, particularly polyene antibiotics, have been shown to exert serious untoward effects $[3,4]$. As there are limited numbers of antifungals available in the market, it is important to find suitable replacements for some of the currently used antifungals [5].

Giloy, Tinospora cordifolia, has been used for centuries in the Ayurvedic and Unani Systems of the Medicine for the treatment of ailments. It has been demonstrated to have antidiabetic, antioxidant, antihepatotoxic, and immunomodulatory properties [6-8]. The aqueous extract of T. cordifolia has been shown to protect against Escherichia coli and Staphylococcus aureus infections $[9,10]$. The active ingredient, G 1-4A, of T. cordifolia stem protected mice against lipopolysaccharideinduced endotoxic shock [11]. It also controlled the drug-resistance Mycobacterium tuberculosis by modulating the immune responses [12]. Recently, we showed that aqueous and methanolic extracts of T. cordifolia alleviated the Salmonella typhimurium infection in a mouse model [13].

Invasive aspergillosis (IA) caused by Aspergillus fumigatus is a major cause of mortality in immunocompromised persons, including patients with leukemia, undergoing bone marrow, and solid organ transplantation [14]. Treatment of fungal infections has been a challenge for clinicians due to the limited number of antifungals currently available in the market. Recent upsurge in the frequency of azole-resistant $A$. fumigatus isolates has further limited our antifungal armory. On the other hand, polyene antifungals have been shown to exert an acute renal toxicity in the treated subjects. Thus, it is important to find a plant-derived broad-spectrum antifungal agents that can be used to treat infectious fungal diseases. In the present study, we used T. cordifolia aqueous extract (TCAE) against A. fumigatus both in vitro and in a mouse model. The results of the present study demonstrated that TCAE effectively alleviated the systemic infection of $A$. fumigatus in the mouse model.

\section{MATERIALS AND METHODS}

Materials

Sabouraud Dextrose Agar (SDA) was purchased from HiMedia Pvt. Ltd. Mumbai, India. Amphotericin B was purchased from Sigma-Aldrich (St. Louis, Mo, USA).

\section{Mice}

BALB/C mice of 10-12 weeks of age were used in this study. Mice were purchased from the animal house facility of King Saud University, Riyadh, Saudi Arabia. The techniques used for bleeding, injection, and sacrifice of animals were approved by an Animal Ethics Committee of the College of Applied Medical Sciences, Qassim University, Buraydah.

\section{Preparation of extracts from the stems of $T$. cordifolia}

The dried stems of T. cordifolia were procured from the registered attar shop in Buraydah, Saudi Arabia. The plant was identified by Dr. Masihuzzama Khan, Assistant Professor in the Department of Pharmacognosy, Unaizah College of Pharmacy, Unaizah, Qassim University. The stems were powdered and TCAE was prepared as described previously [13].

Determination of the antifungal activity

The antifungal activity of TCAE was determined using the agar well diffusion method [13]. Wells (8-mm diameter) were punched in the 
agar. TCAE was dispensed in different wells $(20 \mathrm{mg} / \mathrm{ml})$ and incubated at $37^{\circ} \mathrm{C}$ for $24 \mathrm{~h}$. The antifungal activity of TCAE was assessed by measuring the zone of inhibition. The wells containing amphotericin B $(10 \mathrm{mg} / \mathrm{ml})$ and saline were considered as positive and negative controls, respectively.

Preparation of $A$. fumigatus for infection

A. fumigatus was cultured as described in the previous section. Each mouse was infected through the intravenous route with a lethal dose of $7 \times 10^{5}$ viable $A$. fumigatus spores [14]

Treatment of $A$. fumigatus-infected mice with AETC

Mice were treated with various doses $(10,25$, and $50 \mathrm{mg} / \mathrm{kg})$ of TCAE orally for 7 days (day 1-7) after A. fumigatus infection (day 0). Mice were divided into the following groups: (1) Saline, (2) TCAE - $10 \mathrm{mg} / \mathrm{kg}$, (3) TCAE - $25 \mathrm{mg} / \mathrm{kg}$, and (4) TCAE - $50 \mathrm{mg} / \mathrm{kg}$. Each group was comprised of 10 mice.

Prophylactic use of TCAE against $A$. fumigatus

To determine the prophylactic effect of TCAE against $A$. fumigatus, mice were pre-treated (PT) for 3 consecutive days ( $-3--1$ days) with a dose of $10 \mathrm{mg} / \mathrm{kg}$ of AETC. On day 0 , mice were infected with $7 \times 10^{5}$ viable A. fumigatus spores through intravenous route. Treatment with $200 \mu \mathrm{l}$ of 10,25 , and $50 \mathrm{mg} / \mathrm{kg}$ of doses of TCAE was given for 7 days to A. fumigatusinfected mice that were prophylactically treated or untreated with TCAE $(10 \mathrm{mg} / \mathrm{kg})$. Mice were divided into following groups: (1) Saline, (2) PT + TCAE - $10 \mathrm{mg} / \mathrm{kg}$, (3) TCAE - $10 \mathrm{mg} / \mathrm{kg}$, (4) PT + TCAE - $10 \mathrm{mg} / \mathrm{kg}+$ TCAE - $10 \mathrm{mg} / \mathrm{kg}$, (5) TCAE - $25 \mathrm{mg} / \mathrm{kg}$, (6) PT + TCAE - $10 \mathrm{mg} / \mathrm{kg}+$ TCAE - $25 \mathrm{mg} / \mathrm{kg}$, (7) TCAE - $50 \mathrm{mg} / \mathrm{kg}$, and (8) PT + TCAE - $10 \mathrm{mg} / \mathrm{kg}$ + TCAE - $50 \mathrm{mg} / \mathrm{kg}$.

\section{Quantitative analysis of $A$. fumigatus in the kidney}

The severity of $A$. fumigatus infection was assessed by determining the fungal load in the kidney of mice untreated or treated with T. cordifolia extract. Three mice from each group were sacrificed on day 3 post-A. fumigatus infection, and their kidneys were taken out aseptically as described earlier [14]. Briefly, weighed portions of the kidney tissues were homogenized in $5 \mathrm{ml}$ of sterile normal saline, and different dilutions of the suspension were plated on SDA plates. The plates were incubated at $37^{\circ} \mathrm{C}$ for $48 \mathrm{~h}$. The numbers of viable $A$. fumigatus colonies were counted and the fungal load was determined by multiplying by the dilution factor.

\section{Statistical analyses}

Analysis of the survival of mice was performed using Kaplan-Meier curve, and various groups were compared by the log-rank test. Fungal burden (colony-forming units [CFU]) in the kidney was analyzed by one-way ANOVA using GraphPad Prism software version 5.0.

\section{RESULTS}

The aqueous extract of $T$. cordifolia shows in vitro antifungal activity The aqueous extract of $T$. cordifolia showed potent activity against A. fumigatus, Aspergillus Flavus, and Aspergillus niger used in the study. A zone of inhibition was calculated as the percentage antifungal activity of amphotericin B (100\%). Table 1 shows that T. cordifolia extracts showed the antifungal activity against all three strains of Aspergillus.

Treatment with TCAE results in increased survival of A. fumigatus-infected mice

The therapeutic effect of TCAE was determined by treating $A$. fumigatus-infected mice with the doses of 10,25 , and $50 \mathrm{mg} / \mathrm{kg}$ of TCAE for 7 consecutive days. Mice were observed for 40 days for their survival. All A. fumigatus-infected mice in the untreated group died by day 10. A. fumigatus-infected mice in the groups treated with 25 and $50 \mathrm{mg} / \mathrm{kg}$ of TCAE showed $30 \%$ and $40 \%$ survival, respectively (Fig. 1). The survival rate of mice in the group treated with TCAE at a dose of $50 \mathrm{mg} / \mathrm{kg}$ was found to be significantly greater as compared to that of mice in the untreated group $(\mathrm{p}<0.01)$.
Table 1: The antifungal activity of TCAE

\begin{tabular}{ll}
\hline Name of the organism & $\begin{array}{l}\text { Percentage inhibition of } \\
\text { amphotericin B }\end{array}$ \\
\hline Aspergillus fumigatus & $52 \pm 6.6$ \\
Aspergillus flavus & $56 \pm 8.2$ \\
Aspergillus niger & $42 \pm 6.5$ \\
\hline
\end{tabular}

The data represent mean of three different experiments \pm S.D, TCAE: Tinospora cordifolia aqueous extract

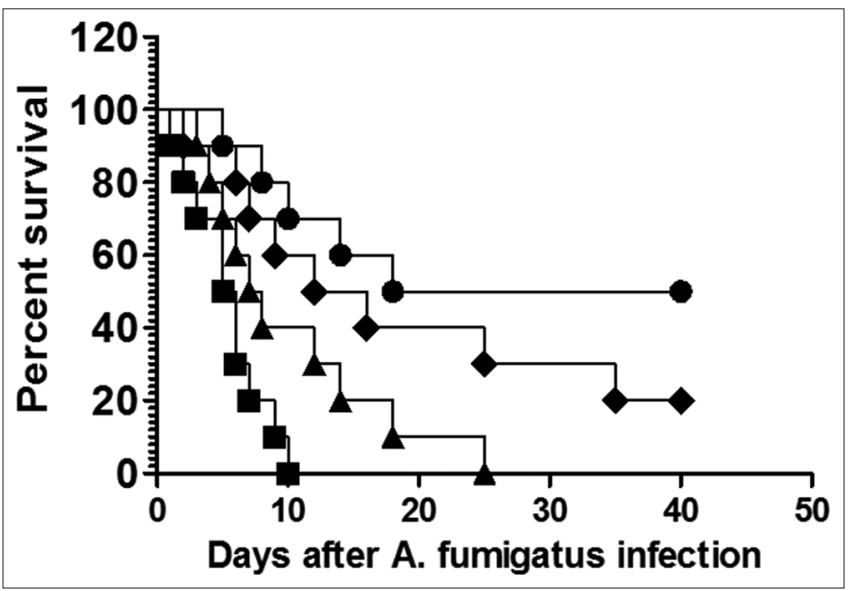

Fig. 1: Tinospora cordifolia aqueous extract (TCAE) increases the survival of the Aspergillus fumigatus-infected mice. Mice were infected with $7 \times 10^{5}$ colony-forming units of $A$. fumigatus through intravenous route. Treatment with the doses of 10, 25 and $50 \mathrm{mg} / \mathrm{kg}$ of TCAE was given for consecutive 7 days' postinfection. Mice were observed for $\mathbf{4 0}$ days for their survival; saline (घ), TCAE - $10 \mathrm{mg} / \mathrm{kg}(\Delta)$, TCAE - $25 \mathrm{mg} / \mathrm{kg}(\bullet)$, TCAE - $50 \mathrm{mg} / \mathrm{kg}$

$(\bullet)$. Untreated control versus TCAE - $50 \mathrm{mg} / \mathrm{kg}(\mathrm{p}<0.01)$

Mice treated with TCAE showed more resistance against A. fumigatus infection

The severity of $A$. fumigatus infection was determined by culturing the tissue homogenates of kidneys of the A. fumigatus-infected mice treated or untreated with TCAE. There were higher CFUs of A. fumigatus in the kidneys of untreated mice (Fig. 2). Mice treated with $50 \mathrm{mg} / \mathrm{kg}$ of TCAE showed least CFUs in their kidney tissue homogenates (Fig. 2).

Prophylactic use of TCAE increases the therapeutic efficacy of the same formulation in combating $A$. fumigatus infection in mice The combination of prophylactic and therapeutic effect of TCAE was assessed by pre-treating the mice with $10 \mathrm{mg} / \mathrm{kg}$ of TCAE for 3 consecutive days before challenging them with $A$. fumigatus. Mice were treated with three doses $(10,25$, and $50 \mathrm{mg} / \mathrm{kg}$ ) of TCAE for 7 consecutive days' post- $A$. fumigatus infection as described in the methods section. The results showed that pre-treatment with TCAE $(10 \mathrm{mg} / \mathrm{kg})$ followed by post-infection treatment with 10,25 , and $50 \mathrm{mg} / \mathrm{kg}$ of TCAE for 7 days resulted in $40 \%, 50 \%$, and $70 \%$ survival, respectively, on day 40 (Fig. 3). The mice that received only TCAE pretreatment also showed increased survival compared to untreated mice (Fig. 3).

The assessment of the severity of Aspergillosis in the group of immunocompetent mice pre-treated with TCAE showed much reduced fungal loads in their kidneys compared to mice in other groups. Mice that were only PT with TCAE also resisted A. fumigatus infection as shown by lower fungal load in their kidneys compared to mice not receiving any TCAE pretreatment (Fig. 4). The group of immunocompetent mice pre-treated with TCAE followed by treatment with $50 \mathrm{mg} / \mathrm{kg}$ of TCAE showed the least CFU counts in their kidneys (Fig. 4). 


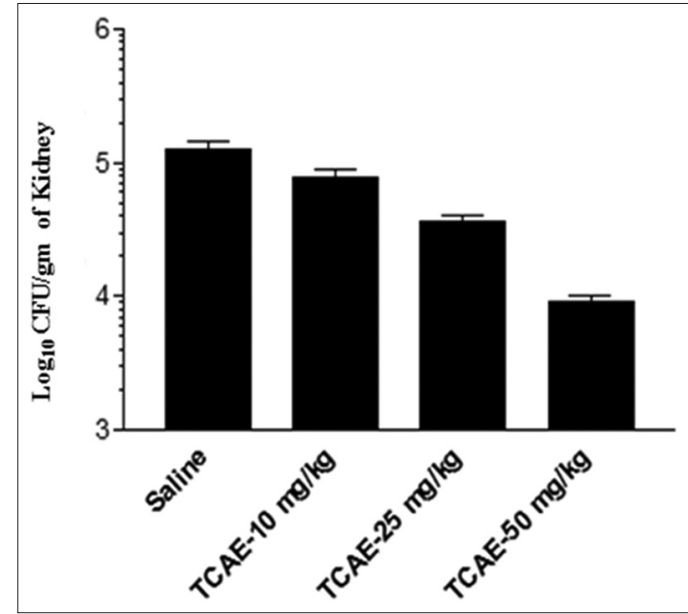

Fig. 2: Treatment with Tinospora cordifolia aqueous extract (TCAE) reduces the fungal burden in the kidney of Aspergillus fumigatusinfected mice. Mice were infected with $7 \times 10^{5}$ colony-forming units of $A$. fumigatus through intravenous route. Treatment with various doses $(10,25$, and $50 \mathrm{mg} / \mathrm{kg})$ of TCAE was given for consecutive 7 days' post- $A$. fumigatus infection. On day 3 post- $A$. fumigatus infection, three mice from each untreated or treated group were sacrificed and the kidneys were taken out for homogenization. The kidney tissue homogenates were cultured to determine the fungal burden. Untreated control versus TCAE-50 $\mathrm{mg} / \mathrm{kg}(\mathrm{p}<0.01)$, untreated control versus TCAE- $25 \mathrm{mg} / \mathrm{kg}(\mathrm{p}<0.05)$

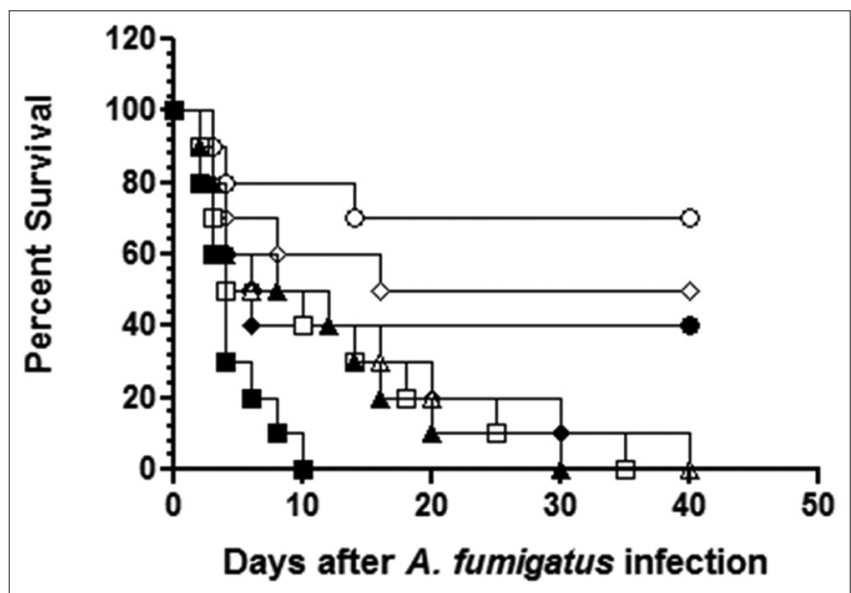

Fig. 3: The combination of prophylactic and therapeutic use of Tinospora cordifolia aqueous extract (TCAE) was more effective in the treatment of Aspergillus fumigatus infection in mice. Mice were pre-treated with a dose of $10 \mathrm{mg} / \mathrm{kg}$ of TCAE for consecutive 3 days. After pre-treatment with TCAE, mice were infected with $7 \times 10^{5}$ colony-forming units of $A$. fumigatus through intravenous route. Treatment with various doses $(10,25$, and $50 \mathrm{mg} / \mathrm{kg})$ of TCAE was given for consecutive 7 days' post-infection. Mice were observed for $\mathbf{4 0}$ days to monitor their mortality and morbidity.

Saline ( $)$ ) TCAE - $10 \mathrm{mg} / \mathrm{kg}(\Delta)$, PT + TCAE - $10 \mathrm{mg} / \mathrm{kg}(\square)$,

PT + TCAE - $10 \mathrm{mg} / \mathrm{kg}+$ TCAE - $10 \mathrm{mg} / \mathrm{kg}(\triangle)$, TCAE - $25 \mathrm{mg} / \mathrm{kg}(\bullet)$, PT + TCAE - $10 \mathrm{mg} / \mathrm{kg}+$ TCAE - $25 \mathrm{mg} / \mathrm{kg}(\diamond)$, TCAE - $25 \mathrm{mg} / \mathrm{kg}(\circ)$, PT + TCAE - $10 \mathrm{mg} / \mathrm{kg}+$ TCAE - $25 \mathrm{mg} / \mathrm{kg}$ (匹). Untreated control versus PT-TCAE + TCAE - $25 \mathrm{mg} / \mathrm{kg}(\mathrm{P}<0.05)$, Untreated control versus TCAE-50 $\mathrm{mg} / \mathrm{kg}(\mathbf{p}<0.05)$, untreated control versus PTTCAE + TCAE-50 mg/kg $(p<0.01)$

\section{DISCUSSION}

In the recent years, the antibiotic resistance ability of $A$. fumigatus has contributed to increased frequency of Aspergillosis in human

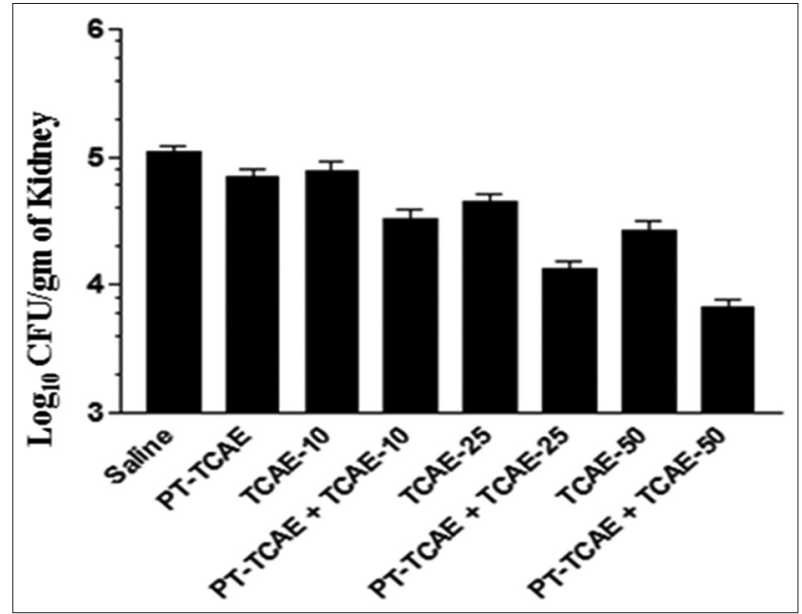

Fig. 4: Prophylactic treatment with Tinospora cordifolia aqueous extract (TCAE) increases the therapeutic efficacy of the same formulation against Aspergillus fumigatus. Mice were PT with a dose of $10 \mathrm{mg} / \mathrm{kg}$ of TCAE for consecutive 3 days.

After pre-treatment with TCAE, mice were infected with $7 \times 10^{5}$

CFU of $A$. fumigatus through intravenous route. Treatment

with various doses $(10,25$, and $50 \mathrm{mg} / \mathrm{kg})$ of TCAE was given for consecutive 7 days' post-infection. On day 3 post- $A$. fumigatus infection, three mice from each untreated or treated group were sacrificed and the kidneys were taken out for homogenization. The kidney tissue homogenates were cultured to determine fungal burden. Untreated control versus PT-TCAE + TCAE - $50 \mathrm{mg} / \mathrm{kg}(\mathrm{p}<0.05)$, untreated control versus PT-TCAE

+ TCAE - $25 \mathrm{mg} / \mathrm{kg}(\mathrm{p}<0.01)$, untreated control versus TCAE - $50 \mathrm{mg} / \mathrm{kg}(\mathrm{p}<0.05)$, untreated control versus PT - TCAE + TCAE - $50 \mathrm{mg} / \mathrm{kg}(\mathrm{p}<0.001)$

population [15]. The use of plants and their bioactive constituents has emerged as a promising alternative to traditional drugs in the treatment of fungal infections [16]. We have earlier shown that thymoquinone, a major bioactive constituent of Nigella sativa seeds, possesses a strong activity against Candida albicans in a mouse model [16]. Due to the problem of antibiotic resistance and prevalence of immune suppression, the treatment of Aspergillosis is posing a big threat to human society. Plant-derived antifungal agents can selectively act on various targets with fewer side effects. Since there are less chances of fungal resistance against herbal preparations due to their multiple mechanisms of action, the use of medicinal plants may be proved a better option for the treatment of drug-resistant Aspergillosis.

In the present study, the aqueous extract of T. cordifolia showed its activity against different Aspergillus spp. including A. fumigatus, A. flavus, and A. niger. TCAE was tested against A. fumigatus, A. flavus, and $A$. niger in in vitro studies and was effective in inhibiting the growth of these fungi. This encouraged us to use TCAE against $A$. fumigatus in a murine model. Interestingly, the result of in vivo studies confirmed the activity of TCAE against $A$. fumigatus. A. fumigatus-infected mice showed increased survival and less fungal load in their kidney tissues after treatment with TCAE, particularly at higher doses.

T. cordifolia and its constituents have been shown to possess immunostimulating activities [13]. An $\alpha$-D-glucan, a constituent found in T. cordifolia, has shown its efficacy in stimulating NK cells, B cells, and $\mathrm{T}$ cells with simultaneous production of various immune-stimulatory cytokines. This stimulation of immune cells can play a very crucial role in combating the fungal infectious diseases. We have recently shown that both aqueous and methanolic extracts of T. cordifolia stimulate the secretion of important cytokines by macrophages that contribute to the elimination of $S$. typhimurium infection from mice [13]. The immunestimulating effect of $T$. cordifolia is also evident from the results of 
our in vivo studies as the combination of prophylactic and therapeutic use of TCAE was most effective against A. fumigatus. Thus, the use of T. cordifolia extracts for the treatment of Aspergillosis seems to have superiority over commonly used antibiotics as earlier possesses both immunostimulatory and antifungal activities.

Extensive use of antibiotics causes systemic toxicity and immune suppression in the treated patients and predisposes them to opportunistic bacterial and fungal infections. The use of herbal medicine minimizes the chances of toxicity, which may support its use for extended periods. Although more extensive studies are needed before considering $T$. cordifolia as an attractive and safe option in the treatment for Aspergillosis. Furthermore, this preparation may also be studied for its implications to treat other opportunistic infections in immunocompromised persons due to its immunopotentiating properties.

\section{CONCLUSIONS}

The results of the present study suggest that some bioactive constituents present in TCAE may be responsible for its activity against $A$. fumigatus. It is essential that further study should be continued to isolate and purify the bioactive components of $T$. cordifolia that are responsible for antifungal activity.

\section{ACKNOWLEDGMENT}

We are highly thankful to the College of Applied Medical Sciences, Qassim University to provide necessary facilities.

\section{AUTHORS' CONTRIBUTIONS}

Dr. Masood A. Khan designed and performed the experiments, analyzed the data, and wrote the manuscript.

\section{CONFLICTS OF INTEREST}

Authors do not have any conflicts of interest.

\section{REFERENCES}

1. Alekshun MN. New advances in antibiotic development and discovery. Expert Opin Invest Drug 2005;14:117-34.
2. Conly J, Rennie R, Johnson J, Farah S, Hellman D. Disseminated candidiasis due to amphotericin B resistant Candida albicans. J Infect Dis 1992;165:761-64.

3. Tujios S, Fontana RJ. Mechanism of drug-induced liver injury: From bedside to bench. Nat Rev Gastroenterol Hepatol 2011;8:202-11.

4. Khan MA, Owais M. Toxicity, stability and pharmacokinetics of amphotericin B in immunomodulator tuftsin-bearing liposomes in a murine model. J Antimicrob Chemother 2006;58:125-32.

5. Chapman SW, Sullivan DC, Cleary JD. In search of the holy grail of antifungal therapy. Trans Am Clin Climatol Assoc 2008;19:197-215.

6. Deepti D, Nupur SS. A study on antioxidant and anti-aging properties of few medicinal plants. Int J Pharm Pharm Sci 2016;8:344-7.

7. Fahrizal AS, Ikbar A. Effect of ethanolic extract of Tinospora crispa L. from Indonesia in alloxan induced liver damage. Int J Pharm Pharm Sci 2017;9:65-8

8. Sharma U, Bala M, Kumar N, Singh B, Munshi RK, Bhalerao S. Immunomodulatory active compounds from Tinospora cordifolia. J Ethnopharmacol 2012;141:918-26.

9. Thatte UM, Kulkarni MR, Dahanukar SA. Immunotherapeutic modification of Escherichia coli peritonitis and bacteremia by Tinospora cordifolia. J Postgrad Med 1992;38:13-5.

10. Mishra A, Kumar S, Bhargava A, Sharma B, Pandey AK. Studies on in vitro antioxidant and antistaphylococcal activities of some important medicinal plants. Cell Mol Biol 2011;57:16-25.

11. Desai VR, Ramakrishnan R, Chintalwar GJ, Sainis KB. G1-4A, an immunomodulatory polysaccharide from Tinospora cordifolia, modulates macrophage responses and protects mice against lipopolysaccharide induced endotoxic shock. Int Immunopharmacol 2007; 7:1375-86.0

12. Gupta PK, Chakraborty P, Kumar S, Singh PK, Rajan MG, Sainis KG, et al. G1-4A, a polysaccharide from Tinospora cordifolia inhibits the survival of mycobacterium tuberculosis by modulating host immune responses in TLR4 dependent manner. PLoS One 2016;11:e0154725.

13. Alsuhaibani S, Khan MA. Immune-stimulatory and therapeutic activity of Tinospora cordifolia: Double-edged sword against salmonellosis. J Immunol Res 2017;2017:1787803.

14. Khan MA, Ahmad N, Moin S, Mannan A, Wajahul H, Pasha ST, et al. Tuftsin-mediated immunoprophylaxis against an isolate of Aspergillus fumigatus shows less in vivo susceptibility to amphotericin B. FEMS Immunol Med Microbiol 2005;44:269-76.

15. Wiederhold NP. Antifungal resistance: Current trends and future strategies to combat. Infect Drug Resist 2017;10:249-59.

16. Khan MA, Aljarbou AN, Khan A, Younus H. Liposomal thymoquinone effectively combats fluconazole-resistant Candida albicans in a murine model. Int J Biol Macromol 2015;76:203-8. 